\title{
PEER TUTORING AS LEARNING STRATEGY FOR CLINICAL PRACTICE TO IMPROVE THE CRITICAL THINKING AMONG NURSING STUDENTS: A SYSTEMATIC REVIEW
}

\author{
Kristina Lisum \\ Doctoral Program of Nursing, Faculty of Health Sciences, Universitas Indonesia
}

\begin{abstract}
Background: Implementation of nursing practice occurs at variety setting. Unfortunately, nursing students had highest stress in the clinical setting for assignment and workload, hence academe is criticized not prepare students to participate in patient care. Nursing educator need to provide various learning strategy to achieve goals, such as peer tutoring. Peer tutoring is one of learning strategy that could be implemented in the clinical setting. In Indonesia, this strategy is under reported by nursing students. Benefits have been reported when students and health school are implementing peer tutoring. This study aimed to systematically review about peer tutoring as learning strategy for clinical practice to improve the critical thinking among nursing students.

Subjects and Method: A systematic review was conducted using electronic database of ProQuest. The keywords used in this study were "peer tutor" AND "clinical practice" AND "critical thinking". The articles were collected from 2015 to 2019, in the health area. The data were collected by table and collated in a narrative summary.

Results: Sixteen articles met the inclusion criteria. The studies reported positive outcome on implementing peer tutor, such as increased confidence, stronger critical thinking, and also improved skills. Unfortunately, if students learning style was not compatible with peer tutoring, the students will become more individualized with the clinical instructor, negating its potential benefit.

Conclusion: The peer tutoring as learning strategy increases confidence, critical thinking, and skills among nursing students. However, the variety of peer tutoring must be evaluated clearly so it can impact not only for nursing students but also for nursing school.
\end{abstract}

Keywords: peer tutoring, clinical practice, critical thinking

Correspondence:

Kristina Lisum. Doctoral Program of Nursing, Faculty of Health Sciences, Universitas Indonesia. Email: kristinalisum@gmail.com. Mobile: 08128202546.

The $6^{\text {th }}$ International Conference on Public Health

Best Western Premier Hotel, Solo, Indonesia, October 23-24, 2019 | 247

https://doi.org/10.26911/the6thicph.04.09 